\title{
Cost-effectiveness Analysis of Helicobacter pylori Eradication Therapy in First-Degree Relatives of Patients with Gastric Cancer
}

This article was published in the following Dove Press journal: Patient Preference and Adherence

\author{
Hanrui Zheng ${ }^{1, *}$ \\ Qian $\mathrm{Xie}^{2, *}$ \\ Mei Zhan' \\ Chaohui Jin' \\ Qiu $\mathrm{Li}^{3,4}$
}

\begin{abstract}
'Department of Pharmacy, West China Hospital, Sichuan University, Chengdu, People's Republic of China; ${ }^{2}$ International Medical Center/Ward of General Practice, West China Hospital, Sichuan University, Chengdu, People's Republic of China; ${ }^{3}$ Department of Medical

Oncology, Cancer Center, West China Hospital, Sichuan University, Chengdu, People's Republic of China; ${ }^{4}$ West China Biomedical Big Data Center, Sichuan University, Chengdu, People's Republic of China
\end{abstract}

*These authors contributed equally to this work

Correspondence: Chaohui Jin

Department of Pharmacy, West China

Hospital, Sichuan University, Chengdu,

People's Republic of China

Tel +86-28-85421763

Email695025422@qq.com

Qiu Li

Department of Medical Oncology, Cancer Center, State Key Laboratory of

Biotherapy, West China Hospital, Sichuan University, Chengdu, People's Republic of China

Tel +86-28-85423262

Email fbqiu9@163.com
Background: Helicobacter pylori (H. pylori) eradication therapy has been shown to reduce the risk of gastric cancer in patients who have a family history of gastric cancer in firstdegree relatives. The aim of this study was to assess the cost-effectiveness of $H$. pylori eradication therapy in a select population in the People's Republic of China.

Methods: A Markov model was applied to evaluate the cost-effectiveness of $H$. pylori eradication therapy. The long-term costs of $H$. pylori eradication therapy were calculated from the Chinese perspective. Health outcomes were measured by quality-adjusted life years (QALYs). Epidemiological information and health utilities used in the model were collected from published literatures or statistical bureaus. A sensitivity analysis was conducted to explore the influence of parameters on the uncertainty of the model.

Results: Compared with the no eradication therapy group, H. pylori eradication therapy prolonged an average of 4.52 QALYs (32.64 QALYs vs 28.12 QALYs) and saved \$3227.07 (\$2472.83 vs \$5699.90). The cost-effectiveness analysis demonstrated that no $H$. pylori eradication therapy cost more and produced less QALYs. It was dominated by $H$. pylori eradication therapy. The one-way sensitive analyses proved that the results were robust to the fluctuations of the input parameters.

Conclusion: H. pylori eradication therapy not only reduced the risk of gastric cancer in first-degree relatives of patients with gastric cancer but also was an economical strategy with lower costs and greater efficacy.

Keywords: Helicobacter pylori, eradication therapy, gastric cancer, cost-effectiveness analysis

\section{Introduction}

Currently, cancer remains an important focus of public health, and gastric cancer is the third cause of cancer-related death. ${ }^{1}$ Helicobacter pylori (H. pylori) is a Gramnegative bacterium, which could colonize in the stomach leading to gastric cancer and gastric mucosa-associated lymphoid tissue lymphoma. ${ }^{2}$ As the most common infectious agent, $H$. pylori contributes to approximately $89 \%$ non-cardia gastric cancer in the world. ${ }^{3}$ The People's Republic of China is the most populous country in the world, with an approximately $56 \%$ prevalence of $H$. pylori infection, accounting for more than $40 \%$ of global gastric cancer-related deaths. ${ }^{4-6}$

Considering that $H$. pylori plays an important role in gastric cancer, eradication therapy for $H$. pylori infected patients is an effective measure to decrease the incidence of gastric cancer. The Kyoto global consensus report agreed that 
eradication therapy of $H$. pylori infection was a primary strategy for preventing gastric cancer, which could reduce the risk of gastric cancer. ${ }^{7}$ However, it is challenging to actively screen and treat all $H$. pylori-positive patients on a national scale in countries where $H$. pylori infection is highly prevalent in reality. In fact, the indication of $H$. pylori screening and eradication is influenced by clinical judgment and the patient's condition. H. pylori-infected patients who can reap more benefits from H. pylori eradication therapy are recommended for treatment. Peptic ulcer (regardless of activity or complications), chronic gastritis with dyspepsia and family history of gastric cancer had been listed as $H$. pylori eradication indications in the Fifth Chinese National Consensus Report. ${ }^{8}$ Although the fact that individuals with a family history of gastric cancer had strong correlation to gastric cancer, not all consensus or guidelines recommended the relatives of gastric cancer patients to receive routine screening for $H$. pylori infection and eradication therapy due to insufficient evidence. ${ }^{9-11}$ Recently, a research in Korea demonstrated that $H$. pylori eradication therapy in $H$. pylori-infected patients who had a family history of gastric cancer in first-degree relatives reduced the risk of gastric cancer. ${ }^{12}$ In this research, 1,676 individuals were randomly assigned to two groups. Therein, $1.2 \%$ in the $H$. pylori eradication therapy group and $2.7 \%$ in the placebo group developed gastric cancer (hazard ratio, 0.45; $95 \%$ confidence interval, 0.21 to $0.94 . P=0.03$ by $\log$ rank test).

Nevertheless, whether H. pylori eradication therapy is cost-effective is unknown in these populations. The following concern has been raised about its application. Adverse events including diarrhea and vomiting induced by H. pylori eradication therapy may have an impact on the quality of life. Costs of drugs, costs of screening for H. pylori also cause economic burden for these people. Another concern is that the heavy antibiotic consumption would worsen antibiotic resistance. On account of these factors, conducting a cost-effectiveness analysis to estimate $H$. pylori eradication is of great importance, especially in countries with high $H$. pylori prevalence. The aim of our research was to evaluate the cost-effectiveness of eradication therapy for $H$. pylori-infected patients who had a family history of gastric cancer in first-degree relatives from a healthcare payer perspective in the People's Republic of China.

\section{Methods}

\section{Clinical Information}

Clinical information was derived from a randomized trial performed in Korea. ${ }^{12}$ The eligibility criterion was H. pylori-positive persons older than 40 years who had at least a first-degree relative with gastric cancer. A total of 1,676 people were randomly divided into two groups: one received eradication therapy and the other received placebo therapy. Patients in both groups received endoscopic monitoring every 2 years. These two groups had no significant differences in age, sex or other basic characteristics at baseline. The status of $H$. pylori infection was evaluated based on a rapid urease test and WrightGiemsa staining of biopsy specimens. After follow-up, H. pylori was eradicated in 551 of 786 patients in the treatment group. Participants who still had H. pylori infection received bismuth-based quadruple therapy (a proton-pump inhibitor, bismuth, metronidazole, and tetracycline) for 10 days after the trial ended. Gastric cancer was confirmed by the use of biopsy in 5 of 608 H. pylori-negative participants, and 28 of $979 \mathrm{H}$. pyloripositive participants.

\section{Decision Model}

We used the TreeAge Pro (TreeAge Software, Williamstown, MA, USA) to construct a Markov model, which compared two treatment strategies: 1) subjects received eradication therapy $(30 \mathrm{mg}$ lansoprazole, $1000 \mathrm{mg}$ amoxicillin, and $500 \mathrm{mg}$ clarithromycin, each taken twice daily for 7 days); and 2) subjects received no therapy. The treatment group comprised four exclusive health states (H. pylori infection, H. pylori eradication, gastric cancer, dead) and the control group comprised three exclusive health states (H. pylori infection, gastric cancer, dead). These health states in the Markov model were applied to simulate the disease process of $H$. pyloriinfected patients (Figure 1).

\section{Model Parameters}

Transition probabilities were calculated by the formula: Probability $=1-\exp (-\mathrm{rt})$, where $\mathrm{r}$ is the incidence of event over time period t. ${ }^{13}$ The parameters in the model such as the eradication rate of $H$. pylori and the incidence of gastric cancer in first-degree relatives of patients with gastric cancer were derived from the clinical trial in South Korea. ${ }^{12}$ We ignored the recurrence rate after $H$. pylori eradication, because it was rare with an annual incidence of $1.75 \%{ }^{14}$ 

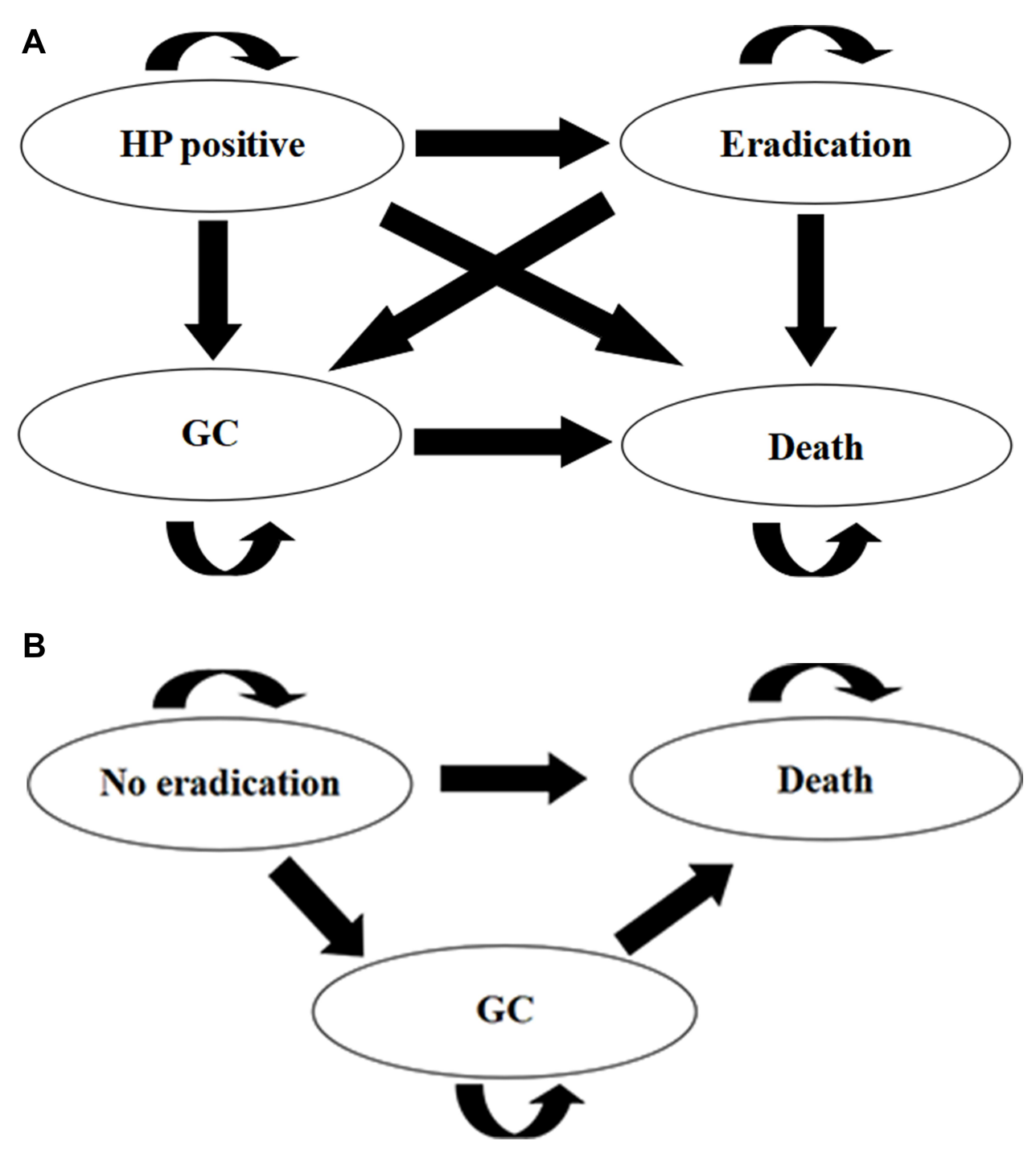

Figure I The Markov model was used to compare two strategies comprising health states. (A) Eradication therapy group. (B) No eradication therapy group. Abbreviations: HP, Helicobacter pylori; GC, gastric cancer.

The population mortality was obtained from the China Statistics Bureau and the mortality of gastric cancer was 22.5 per 100,000 people. $^{5}$ Therefore, the mortality rate for non-gastric cancer was approximately $6.92 \%$. The 5 -year survival rate of gastric cancer patients in the People's Republic of China was $35.9 \% .^{15}$ By using the following formula: $\mathrm{P}=\mathrm{Pt}^{(1 / t)}$, the mortality rate of gastric cancer patients was about $19 \%$ per year. Details are shown in Table 1 . The model cycle was 1 year. Based on the average life expectancy of 76.34 years in the People's Republic of China, the operation time of this model was set at 40 years.

\section{Costs and Utilities}

Only direct costs included were calculated. The costs of H. pylori eradication therapy, costs of endoscopy screening, costs of $H$. pylori testing, and costs of adverse events management were estimated based on the prices in Sichuan province, the People's Republic of China. Costs of gastric cancer treatment were derived from a multicenter cross-sectional survey. ${ }^{16}$ All costs were converted into US dollars and quality-adjusted life years (QALYs) were used to measure health outcomes. The discount of costs and QALYs was 3\% each year. We assumed that the health utility of participants who successfully eradicated H. pylori was 1 . The health utilities of patients with H. pylori infection and gastric cancer came from the published literature, and were 0.89 and 0.38 , respectively. ${ }^{17}$

\section{Sensitivity Analysis}

A sensitivity analysis was performed to explore the impact of parameters fluctuation on the robustness of the results. 
Table I Base Parameters in the Markov Model

\begin{tabular}{|c|c|c|}
\hline Parameters & Value & Source \\
\hline \multicolumn{3}{|l|}{ Clinical variables } \\
\hline H. pylori prevalence rate & $56 \%$ & [2] \\
\hline Incidence of gastric cancer in & $2.9 \%$ & {$[13]$} \\
\hline H. pylori-positive population (\%) & & \\
\hline $\begin{array}{l}\text { Incidence of gastric cancer in } \mathrm{H} \text {. pylori } \\
\text { eradication population (\%) }\end{array}$ & $0.8 \%$ & {$[13]$} \\
\hline Success $H$. pylori eradication rate (\%) & $70.10 \%$ & [13] \\
\hline Population mortality (\%॰) & $7.14 \%$ & $\begin{array}{l}\text { National Bureau } \\
\text { of Statistics of } \\
\text { China }\end{array}$ \\
\hline Nongastric cancer mortality rate (\%o) & $6.92 \%$ & \\
\hline $\begin{array}{l}\text { Five-year survival rate for gastric } \\
\text { cancer (\%) }\end{array}$ & $35.9 \%$ & {$[16]$} \\
\hline \multicolumn{3}{|l|}{ Costs variables $(\$)$} \\
\hline H. pylori eradication therapy & 77.83 & \\
\hline Gastric cancer screening & 29.96 & \\
\hline H. pylori testing & 81.85 & \\
\hline AEs of eradication therapy & 1.99 & \\
\hline $\begin{array}{l}\text { Average annual gastric cancer } \\
\text { treatment }\end{array}$ & 9891 & {$[17]$} \\
\hline \multicolumn{3}{|l|}{ Health utility } \\
\hline After $H$. pylori eradication & 1 & \\
\hline H. pylori infection & 0.89 & [18] \\
\hline Gastric cancer & 0.38 & [18] \\
\hline
\end{tabular}

Note: H. pylori, Helicobacter pylori.

Abbreviation: $\mathrm{AE}$, adverse events.

Probabilistic sensitivity analysis was conducted using the Monte Carlo simulation to iterate 1,000 times. The analysis results are shown by incremental cost-effect scatter plots.

\section{Results}

\section{Base Case Analysis}

The baseline results of our analysis are presented in Table 2. Within a 40-year time horizon, H. pylori eradication therapy in first-degree relatives of patients with gastric cancer yielded more benefits than no eradication therapy (32.64 QALYs vs 28.12 QALYs), leading to an extended 4.52 QALYs. It also yielded much lower costs than no eradication therapy ( $\$ 2472.83$ vs $\$ 5699.90)$. Therefore, incremental cost-effectiveness ratio (ICER) of $H$. pylori eradication therapy was $\$-713.95$ per QALY compared to no eradication therapy, indicating that $H$. pylori eradication therapy was in the ascendant for having fewer costs and more benefits.
Table 2 Results of Cost-Effectiveness Analysis

\begin{tabular}{|l|l|l|l|}
\hline Results & $\begin{array}{l}\text { Cost } \\
(\$)\end{array}$ & $\begin{array}{l}\text { Effectiveness } \\
\text { (QALYs) }\end{array}$ & $\begin{array}{l}\text { ICER } \\
\text { (\$/QALY) }\end{array}$ \\
\hline $\begin{array}{l}\text { Eradication } \\
\text { group }\end{array}$ & 2472.83 & 32.64 & Dominant \\
\hline Control group & 5699.90 & 28.12 & \\
\hline
\end{tabular}

Note: Dominant: more effective and less costly than others.

Abbreviations: QALYs, quality adjusted life-years; ICER, incremental costeffectiveness ratio.

\section{Sensitivity Analysis}

With 1,000 Monte Carlo simulations, the incremental costeffectiveness scatterplots of eradication therapy and no eradication therapy are shown in Figure 2. The H. pylori eradication strategy cost less and generated more QALYs than no $H$. pylori eradication. As a result, no H. pylori eradication therapy was dominated by $H$. pylori eradication therapy. One-way sensitivity analyses of selected parameters are displayed in Table 3. The utility of H. pylori-infected people, the incidence of gastric cancer in the H. pylori-positive population, and the costs of gastric cancer treatment were the factors most affecting the results of the model. Although these parameters changed within the range of $\pm 20 \%, H$. pylori eradication therapy produced more QALYs with lower costs, proving that H. pylori eradication therapy remains the dominant strategy. Additionally, we constructed a three-way sensitivity analysis on three parameters that had the greatest impact on the results. When the parameters were the most unfavorable for the implementation of the strategy, H. pylori eradication therapy still rendered net monetary benefit (Figure 3). The results were robust to the ranges of the variables.

\section{Discussion}

Gastric cancer is one of the common malignant tumors, with a fatality rate of up to $75 \%$ in most regions of the world and it is a serious threat to public health. ${ }^{18}$ Of note, the highest fatality rates of gastric cancer are seen in Eastern Asia, especially in the People's Republic of China, Japan and Singapore. ${ }^{19}$ Risk factors of gastric cancer included $H$. pylori-infection, smoking, obesity, food habits and the environment. ${ }^{20}$ As the greatest risk factor for gastric cancer, the World Health Organization has classified $H$. pylori as a group I carcinogen. ${ }^{21,22}$ Another common risk factor of gastric cancer is a family history of gastric cancer. Several studies have found that 


\section{Incremental Cost-effectiveness}

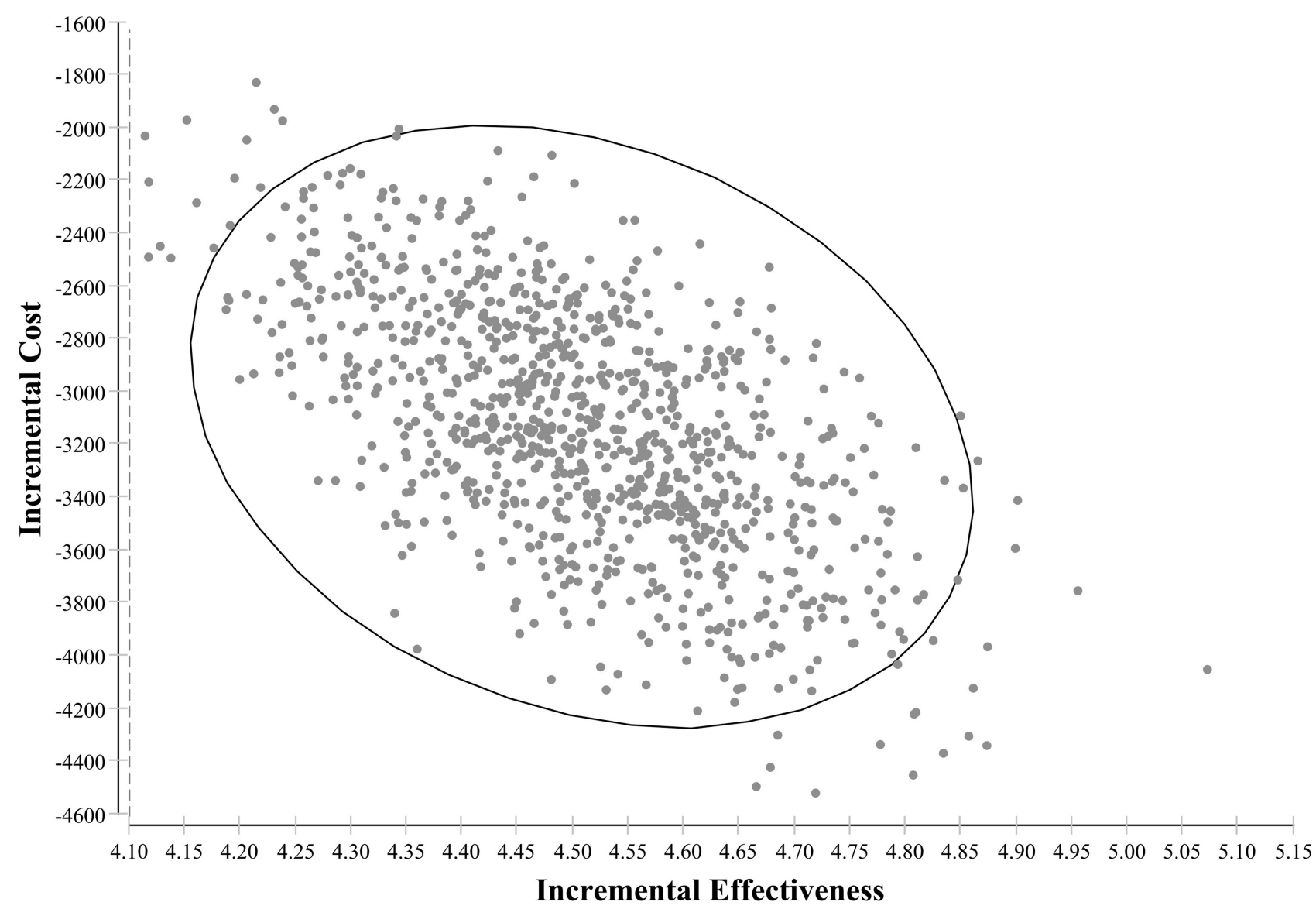

Figure 2 An incremental cost-effectiveness scatterplot comparing eradication therapy with no eradication therapy.

a family history of gastric cancer patients significantly increased the incidence of gastric cancer, especially in first-degree relatives of patients. ${ }^{23}$ The familial clustering of gastric cancer attributed to the shared exposure to carcinogens, eating habits, and genetic susceptibility. ${ }^{24}$ Moreover, $H$. pylori infection and family history of gastric cancer had a synergistic effect on the development of gastric cancer. ${ }^{11}$ The incidence of gastric cancer can be reduced by the management high-risk gastric cancer population. A phase III clinical trial has proved that eradication of $H$. pylori reduced the risk of gastric cancer in firstdegree relatives of patients with gastric cancer. Hence, the implementation of screening and eradication for $H$. pylori is a critical intervention to combat gastric cancer.

To the best of our knowledge, this is the first study to assess the economic influence of $H$. pylori eradication in first-degree relatives of patients with gastric cancer. In this study, we found that $H$. pylori eradication therapy for people who had at least one first-degree relative with gastric cancer resulted in an average of 4.52 longer QALYs (32.64 QALYs vs 28.12 QALYs) and the costs were reduced by $\$ 3,213.05$ ( $\$ 2,472.41$ vs $\$ 5685.46)$. It was proved that $H$. pylori eradication therapy cost less and was more effective compared with no $H$. pylori eradication therapy in the People's Republic of China.

There have been several economic studies focused on H. pylori screening and eradication therapy in Asia. A cost-effectiveness analysis of Chinese in Singapore showed that among the Chinese population with a high incidence of gastric cancer, serology screening and eradication therapy were the dominant strategy compared to no screening. ${ }^{25}$ It was similar to our conclusion that we recommended $H$. pylori screening and eradication therapy for people who had first-degree family history of gastric cancer. Han et a ${ }^{17}$ performed a study to evaluate the costeffectiveness of $H$. pylori screening and eradication therapy in the People's Republic of China, proving that H. pylori screening followed by eradication therapy was 
Table 3 One-Way Sensitivity Analyses of Parameters

\begin{tabular}{|c|c|c|c|c|c|}
\hline & \multicolumn{2}{|c|}{ Eradication Therapy } & \multicolumn{2}{|c|}{ No Eradication Therapy } & \\
\hline & Cost (\$) & Effectiveness (QALYs) & Cost (\$) & Effectiveness (QALYs) & \\
\hline \multicolumn{6}{|c|}{ Costs of gastric cancer treatment $(\$)$} \\
\hline 7912.80 & 2174.85 & 32.64 & 4760.89 & 28.12 & Dominated \\
\hline $11,869.20$ & $2770.8 I$ & 32.64 & 6638.90 & 28.12 & Dominated \\
\hline \multicolumn{6}{|c|}{ Costs of eradication therapy (\$) } \\
\hline 62.26 & 2472.47 & 32.64 & 5699.90 & 28.12 & Dominated \\
\hline 93.40 & 2473.18 & 32.64 & 5699.90 & 28.12 & Dominated \\
\hline \multicolumn{6}{|c|}{ Costs of $H$. pylori testing $(\$)$} \\
\hline 65.48 & 2472.46 & 32.64 & 5687.02 & 28.12 & Dominated \\
\hline 98.23 & 2473.18 & 32.64 & 5699.90 & 28.12 & Dominated \\
\hline \multicolumn{6}{|c|}{ Costs of gastric cancer screening $(\$)$} \\
\hline 23.97 & 2277.07 & 32.64 & 5511.85 & 28.12 & Dominated \\
\hline 35.95 & 2668.58 & 32.64 & 5887.94 & 28.12 & Dominated \\
\hline \multicolumn{6}{|c|}{ Costs of adverse events related to eradication therapy $(\$)$} \\
\hline 1.59 & 2472.79 & 32.64 & 5699.90 & 28.12 & Dominated \\
\hline 2.39 & 2472.86 & 32.64 & 5699.90 & 28.12 & Dominated \\
\hline \multicolumn{6}{|c|}{ Success $H$. pylori eradication rate } \\
\hline $56.08 \%$ & 2513.66 & 32.58 & 5699.90 & 28.12 & Dominated \\
\hline $84.12 \%$ & 2445.42 & 32.68 & 5699.90 & 28.12 & Dominated \\
\hline \multicolumn{6}{|c|}{ Probability of developing gastric cancer in $\mathrm{H}$. pylori-positive population } \\
\hline $0.26 \%$ & 2428.77 & 32.67 & 4812.13 & 28.42 & Dominated \\
\hline $0.38 \%$ & 2516.80 & 32.61 & 6569.05 & 27.83 & Dominated \\
\hline \multicolumn{6}{|c|}{ Probability of developing gastric cancer in $H$. pylori eradication population } \\
\hline $0.69 \%$ & 2226.78 & 32.73 & 5699.90 & 28.12 & Dominated \\
\hline $1.04 \%$ & $27 \mid 7.51$ & 32.55 & 5699.90 & 28.12 & Dominated \\
\hline \multicolumn{6}{|c|}{ Utility of $H$. pylori infection } \\
\hline 0.71 & 2472.83 & 32.48 & 5699.90 & 22.53 & Dominated \\
\hline I & 2472.83 & 32.74 & 5699.90 & 31.57 & Dominated \\
\hline \multicolumn{6}{|c|}{ Utility of gastric cancer } \\
\hline 0.30 & 2472.83 & 32.63 & 5699.90 & 28.08 & Dominated \\
\hline 0.46 & 2472.83 & 32.65 & 5699.90 & 28.16 & Dominated \\
\hline
\end{tabular}

a cost-saving strategy. By this measure, it could save $\$ 168.45$ per QALY per person. Kowada ${ }^{26}$ conducted decision trees to assess the cost-effectiveness of $H$. pylori screening followed by eradication therapy for employees aged 20, 30, 40, 50 and 60 years. Given that it gained more benefits with less costs than no screening, it could be popularized in Japan. Following this study, Kowada ${ }^{27}$ also found that people aged 50 years or older yielded more benefits in $H$. pylori screening than upper gastrointestinal series and endoscopy in high prevalence countries.

A recent consensus in the People's Republic of China announced that $H$. pylori eradication therapy was a cost- 


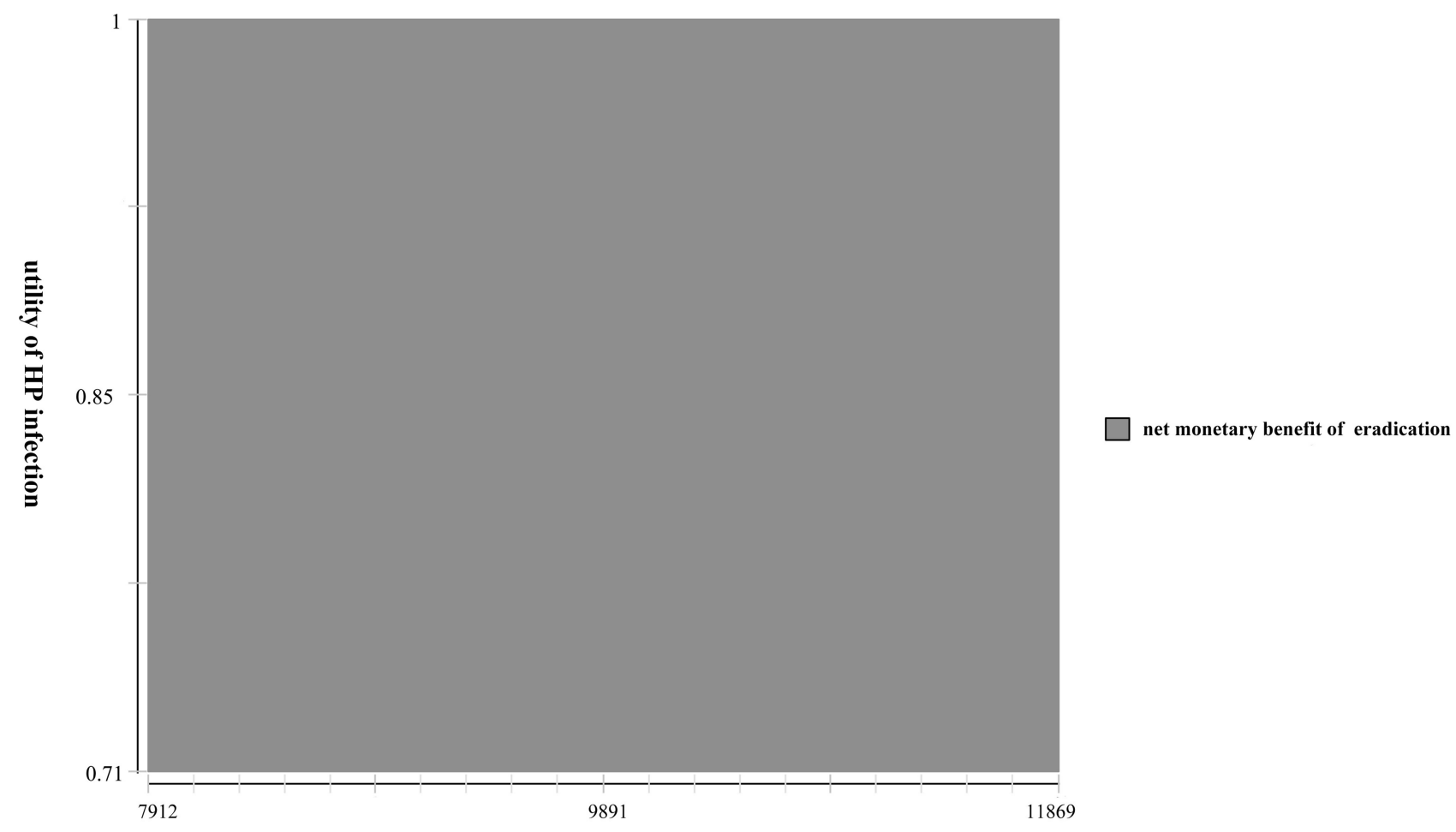

costs of gastric cancer

Figure 3 Sensitivity analysis on utility of HP-infected people and the costs of gastric cancer treatment when the probability of developing gastric cancer in the $H$. pyloripositive population was $0.26 \%$.

Abbreviation: HP, Helicobacter pylori.

effective strategy in high-risk areas. ${ }^{28}$ The main reason for economic gains of $H$. pylori eradication therapy was that it reduced the incidence of gastric cancer, thereby reducing the total costs of gastric cancer. Nevertheless, in addition to the treatment costs, multiple factors including drug availability, and antibiotic resistance needs to be taken into consideration when carrying out a screen-and-treat program for $H$. pylori in the whole country, especially in countries with large populations and limited medical resources. Indeed, H. pylori has an increasing high primary resistance rate of clarithromycin, metronidazole, and levofloxacin in the People's Republic of China. ${ }^{29}$ The universal eradication treatment of $H$. pylori might increase serious antibiotic resistance and affect the application of antibacterial drugs in the future. In addition, the implementation of population-based screening would cause some intangible costs, such as human resources, publicity expenses of health authority. These obstacles have made H. pylori screening and treatment a complicated issue. Our results were similar to the situation described in the previous section and refined the detected population. At the same time, it was relatively easier to implement this program in firstdegree relatives of patients with gastric cancer. Screening and eradication therapy of $H$. pylori infection in a high-risk gastric cancer population is relatively achievable from the perspective of health authorities.

Subjected to the insufficient data, several limitations existed in our analysis that deserve attention. Firstly, the eradication rate of $\mathrm{H}$. pylori and the incidence of gastric cancer in first-degree relatives of patients with gastric cancer used in our study were derived from a singlecenter trial in Korea. Nevertheless, family history of gastric cancer was a global risk factor, so our results may be generally applicable. ${ }^{30}$ Secondly, the utility values of early gastric cancer and advanced gastric cancer may be different. Due to the lack of tumor staging for patients in this trial, we used an average utility of gastric cancer. Thirdly, regarding costs information, we only considered direct costs, neglecting the costs of lost working time and transportation fees. Additionally, the costs of rescue therapy for patients who failed first-line H. pylori therapy, secondary infection after antibiotic treatment and the daily expenses incurred by life extension were not calculated. As a result, the costs may be underestimated. However, they had little effect on the 
results according to the sensitivity analysis. Finally, the characteristics of the population in clinical trials may differ from the patients in clinical practice. Real world studies could be carried out in the future.

In summary, H. pylori eradication therapy significantly reduced the incidence of gastric cancer in first-degree relatives of patients with gastric cancer with economic benefits in the People's Republic of China. Based on our analysis, H. pylori eradication therapy is a dominant strategy. At present, in the People's Republic of China, where disease burden is heavy and economic resources are limited, eradication therapy is a cost-effective prevention strategy to prevent gastric cancer. The persistent $H$. pylori infection not only increased the risk of spreading among people, but also the risk of gastric cancer. It is worthy of being applied and promoted in clinical practice, especially in countries with high $H$. pylori prevalence.

\section{Ethics Approval}

This article does not contain any studies with human participants or animals performed by any of the authors.

\section{Funding}

This study was funded by the National Natural Science Foundation of China (No. 81572988); Science \& Technology Department of Sichuan Province Funding Project (2018SZ0117); the 1.3.5 Project for Disciplines of Excellence, West China Hospital, Sichuan University (ZYJC18008, ZYJC18010).

\section{Disclosure}

The authors report no conflicts of interest in this work.

\section{References}

1. Bray F, Ferlay J, Soerjomataram I, Siegel RL, Torre LA, Jemal A. Global cancer statistics 2018: GLOBOCAN estimates of incidence and mortality worldwide for 36 cancers in 185 countries. CA Cancer J Clin. 2018;68(6):394-424. doi:10.3322/caac.21492

2. Maleki Kakelar H, Barzegari A, Dehghani J, et al. Pathogenicity of Helicobacter pylori in cancer development and impacts of vaccination. Gastric Cancer. 2019;22(1):23-36. doi:10.1007/s10120-018-0867-1

3. Plummer M, Franceschi S, Vignat J, Forman D, de Martel C. Global burden of gastric cancer attributable to Helicobacter pylori. Int J Cancer. 2015;136(2):487-490. doi:10.1002/ijc.28999

4. Feng R-M, Zong Y-N, Cao S-M, Xu R-H. Current cancer situation in China: good or bad news from the 2018 Global Cancer Statistics? Cancer Communications. 2019;39(1):22. doi:10.1186/s40880-0190368-6

5. Chen WQ, Zheng RS, Baade PD, et al. Cancer Statistics in China, 2015. CA: A Cancer Journal for Clinicians. 2016;66(2):115-132. doi:10.3322/caac. 21338
6. Wang F-H, Shen L, Li J, et al. The Chinese Society of Clinical Oncology (CSCO): clinical guidelines for the diagnosis and treatment of gastric cancer. Cancer Communications. 2019;39(1):10. doi:10.1186/s40880-019-0349-9

7. Sugano K, Tack J, Kuipers EJ, et al. Kyoto global consensus report on Helicobacter pylori gastritis. Gut. 2015;64(9):1353-1367. doi:10.1136/gutjnl-2015-309252

8. Liu WZ, Xie Y, Lu H, et al. Fifth Chinese National Consensus Report on the management of Helicobacter pylori infection. Helicobacter. 2018;23(2):e12475. doi:10.1111/hel.12475

9. Chey WD, Leontiadis GI, Howden CW, Moss SF. ACG Clinical Guideline: treatment of Helicobacter pylori Infection. $A m$ J Gastroenterol. 2017;112(2):212-239. doi:10.1038/ajg. 2016.563

10. El-Serag HB, Kao JY, Kanwal F, et al. Houston Consensus Conference on Testing for Helicobacter pylori Infection in the United States. Clin Gastroenterol Hepatol. 2018;16(7):992-1002. doi:10.1016/j.cgh.2018.03.013

11. Choi YJ, Kim N. Gastric cancer and family history. Korean J Intern Med. 2016;31(6):1042-1053. doi:10.3904/kjim.2016.147

12. Choi IJ, Kim CG, Lee JY, et al. Family history of gastric cancer and Helicobacter pylori treatment. $N$ Engl J Med. 2020;382(5):427-436. doi:10.1056/NEJMoa1909666

13. Briggs A, Sculpher M. An introduction to Markov modelling for economic evaluation. Pharmacoeconomics. 1998;13(4):397-409. doi:10.2165/00019053-199813040-00003

14. Xue Y, Zhou L-Y, Lu H-P, Liu J-Z. Recurrence of Helicobacter pylori infection: incidence and influential factors. Chin Med J. 2019;132 (7):765-771. doi:10.1097/CM9.0000000000000146

15. Yang L, Zheng R, Wang N, et al. Incidence and mortality of stomach cancer in China, 2014. Chin J Cancer Res. 2018;30(3):291-298. doi:10.21147/j.issn.1000-9604.2018.03.01

16. Huang H-Y, Shi J-F, Guo L-W, et al. Expenditure and financial burden for common cancers in China: a hospital-based multicentre cross-sectional study. Lancet. 2016;388:10. doi:10.1016/S01406736(16)31937-7

17. Han Y, Yan $T$, Ma H, et al. Cost-effectiveness analysis of Helicobacter pylori eradication therapy for prevention of gastric cancer: a Markov model. Dig Dis Sci. 2019;65(6):1679-1688. doi:10.1007/s10620-019-05910-1

18. Fock KM. Review article: the epidemiology and prevention of gastric cancer. Aliment Pharmacol Ther. 2014;40(3):250-260. doi:10.1111/ apt. 12814

19. Thrift AP, El-Serag HB. Burden of gastric cancer. Clin Gastroenterol Hepatol. 2020;18(3):534-542. doi:10.1016/j. cgh.2019.07.045

20. Karimi P, Islami F, Anandasabapathy S, Freedman ND, Kamangar F. Gastric cancer: descriptive epidemiology, risk factors, screening, and prevention. Cancer Epidemiol Biomarkers Prev. 2014;23 (5):700-713. doi:10.1158/1055-9965.EPI-13-1057

21. Amieva M, Peek RM. Pathobiology of Helicobacter pylori-induced gastric cancer. Gastroenterology. 2016;150(1):64-78. doi:10.1053/j. gastro.2015.09.004

22. Blanchard TG, Czinn SJ. Identification of Helicobacter pylori and the evolution of an efficacious childhood vaccine to protect against gastritis and peptic ulcer disease. Pediatr Res. 2017;81(1-2):170-176. doi:10.1038/pr.2016.199

23. Yusefi AR, Bagheri Lankarani $\mathrm{K}$, Bastani $\mathrm{P}$, Radinmanesh $\mathrm{M}$, Kavosi Z. Risk factors for gastric cancer: a systematic review. Asian Pac J Cancer Prev. 2018;19(3):591-603. doi:10.22034/ APJCP.2018.19.3.591

24. Yu GQ, Hu N, Wang LM, et al. Gastric microbiota features associated with cancer risk factors and clinical outcomes: A pilot study in gastric cardia cancer patients from Shanxi, China. Int $J$ Cancer. 2017;141(1):45-51. doi:10.1002/ijc.30700 
25. Xie F, Luo N, Blackhouse G, Goeree R, Lee H-P. Cost-effectiveness analysis of Helicobacter pylori screening in prevention of gastric cancer in Chinese. Int J Technol Assess Health Care. 2008;24 (1):87-95. doi:10.1017/S0266462307080117

26. Kowada A. Cost-effectiveness of Helicobacter pylori screening followed by eradication treatment for employees in Japan. Epidemiol Infect. 2018;146(14):1834-1840. doi:10.1017/S095026881800208X

27. Kowada A. Cost-effectiveness of Helicobacter pylori test and eradication versus upper gastrointestinal series versus endoscopy for gastric cancer mortality and outcomes in high prevalence countries. Scand J Gastroenterol. 2019;54(6):685-689. doi:10.1080/ 00365521.2019 .1627408
28. Du Y, Zhu H, Liu J, et al. Consensus on eradication of Helicobacter pylori and prevention and control of gastric cancer in China (2019, Shanghai). $J$ Gastroenterol Hepatol. 2020;35(4):624-629. doi:10.1111/jgh.14947

29. Hu Y, Zhu Y, Lu N-H. Primary antibiotic resistance of Helicobacter pylori in China. Dig Dis Sci. 2017;62(5):1146-1154. doi:10.1007/ s10620-017-4536-8

30. Yaghoobi M, McNabb-Baltar J, Bijarchi R, Hunt RH. What is the quantitative risk of gastric cancer in the first-degree relatives of patients? A meta-analysis. World J Gastroenterology. 2017;23 (13):2435-2442. doi:10.3748/wjg.v23.i13.2435

\section{Publish your work in this journal}

Patient Preference and Adherence is an international, peer-reviewed, open access journal that focusing on the growing importance of patient preference and adherence throughout the therapeutic continuum. Patient satisfaction, acceptability, quality of life, compliance, persistence and their role in developing new therapeutic modalities and compounds to optimize clinical outcomes for existing disease states are major areas of interest for the journal. This journal has been accepted for indexing on PubMed Central. The manuscript management system is completely online and includes a very quick and fair peer-review system, which is all easy to use. Visit http:// www.dovepress.com/testimonials.php to read real quotes from published authors. 